\title{
Antropología y Folklore
}

Situándonos dentro de la perspectiva que intentamos dar a este curso, que se basa en el examen de las posibilidades abiertas de relación de la antropología con otras ciencias afines, o con las que coincide sólo en un aspecto particular, es evidente que uno de los campos en que hay una confluencia básica es el de la llamada "cultura popular".

Comenzaremos viendo el surgimiento del estudio del folklore, en paralelo al de la etnología; las diferencias entre ambas disciplinas y, finalmente, las confluencias posibles entre las dos en la actualidad.

\section{EL TÉRMINO FOLKLORE}

Aunque no existe en la antropología cultural, para la cual se esgrimen muy variados orígenes cronológicos y "padres" fundacionales; en el caso del folklore, y si no recurrimos al consabido recurso de que "siempre" ha habido folklore, hay acuerdo en que su primera formulación como área de estudios se produce en el siglo XIX, aunque es evidente la existencia de una tradición anterior a su definición concreta y formal, que se puede hacer arrancar del siglo XVIII (Marcos Arévalo, 1988: 376-377), o de más atrás si se quiere. No obstante, se debe a William John Thoms, aunque con el pseudónimo de Ambrose Merton, la invención del término Folk-Lore que propone en una famosa carta, publicada el 22 de agosto de 1846 en el periódico inglés The Athenaeum (núm. 982: 862-863), para designar *aquel sector del estudio de las antigüedades y la arqueología que abarca el saber tradicional de las clases populares de las naciones civilizadas* ${ }^{1}$.

Sin embargo, desde este mismo origen se produce una confusión terminológica que no ha cesado hasta nuestros días. Porque, folklore es, por una parte, el saber popular (un compuesto cultural) y, por otra, el conocimiento o la ciencia que se ocupa de este sector o fracción de la cultura. Pero, además, y considerando la riqueza derivativa que ha alcanzado el vocablo anglosajón, tendríamos, por una parte, que folklore (o folklórico, folklorismo, etc.) ha llegado a designar precisamente todo lo

1 La famosa carta fue reproducida modernamente por A. Dundes (1965) y traducida al castellano por R. S. Boogs (1945). 
contrario de ciencia y científico, y, por otra parte, que muchos de los recopiladores del saber del pueblo son a la vez folkloristas, porque estudian el folklore, y folklóricos porque tienen especiales cualidades para interpretarlo o reproducirlo, o porque se sienten parte de ese folklore que recogen (Velasco, 1990: 125). De hecho, igual que casi nadie niega su existencia como hecho cultural, no es común la consideración del folklore como materia científica y por tanto, al menos en España, no hay establecido un cauce superior o universitario que permita la profesionalización académica de los folkloristas (Velasco, 1990: 123). Así, y a pesar del éxito obtenido internacionalmente por la palabra folklore (que no deja tampoco de ser una contradicción, ya que se escogió un vocablo extraño para denominar lo más genuino de una nación), el descrédito que la acompaña en los medios académicos ha llevado a la proposición de denominaciones alternativas que, sobre todo entre los antropólogos, revisten a los trabajos de carácter folklórico de una mayor dignidad (artes, costumbres y tradiciones populares, cultura popular y otras menos extendidas entre nosotros como arte verbal) (Velasco, 1988: 18).

Por último, y a este respecto, conviene llamar la atención acerca de muchas definiciones, sobre todo pertenecientes al siglo XIX, en que se insiste en la consideración del "saber popular" como un conocimiento que, opuesto o divergente del "saber científico" moderno, debe ser, sin embargo, valorado y estudiado como el conocimiento producido por determinadas clases o grupos de la civilización occidental; igual de valioso que el acumulado por las élites y las vanguardias, porque se trata de manifestaciones fósiles (o "supervivencias") de otros períodos de la evolución de dicha civilización que, aunque ahora sean consideradas supersticiones, en un momento anterior tenían el mismo valor de la ciencia y, por tanto, forman parte de la historia de nuestra cultura. Por ejemplo, según Machado (1987: 17), lo característico del folklore de una nación, en palabras de G. L. Gomme, que reproduce:

Hállase representado en la historia civilizada [...] por esas costumbres extrañas y al parecer groseras, por las supersticiosas asociaciones con animales, árboles y objetos topográficos con los acontecimientos de la vida humana; por las creencias en brujas, hadas y espíritus; por las baladas y dichos proverbiales referentes á localidades determinadas; por los nombres vulgares conservados á los arroyos, cavernas, grutas, manantiales, torrentes, fuentes y bosques, y, por último, por todo ese extraño saber (Lore) que, si representa hoy una supervivencia, representa también el que fue estado actual de la vida salvaje.

En la práctica, con un carácter más empírico, Machado pensaba que el folklore (o, mejor, el Lore) debía abordarse en un sentido paralelo al 
de las ciencias y por tanto especializado; y así, habría un folklore médico, matemático, botánico, geográfico, meteorológico, etc. (Velasco, 1988: 24-25).

\section{CONTENIDOS DEL FOLKLORE}

Pero no es ésta la única confusión que afecta a la palabra folklore. Incluso en un aspecto fundamental, como es el contenido del folklore, es muy corriente la asimilación con poesía, y literatura en general, música y danza tradicionales; es decir, con solo una parte de ese total saber popular* (Díaz Viana, 1984: 147-148). Si bien la mayoría de los autores insisten en que el folklore incluye todas las creaciones culturales, aprendidas y extendidas de una determinada manera, independientemente de su materialidad o no; es muy frecuente ver como, incluso estos mismos autores, W. Bascom por ejemplo (1974), reducen su ámbito de investigación de hecho a una determinada parte, la más cercana a lo literario (Verbal art, sería la expresión acuñada por el mismo Bascom). Para completar el panorama de la "creación popular" como un todo (es significativa la insistencia en los elementos creativos, es decir, estéticos, centrados en las :artes populares"; como se denominan a veces los museos y algunas investigaciones dedicadas a este tema), es habitual, todavía hoy, la recurrencia a una doble denominación para las investigaciones: "Etnografía y Folklore de .... Tal proceder es bastante antiguo; al menos en España, desde principios de siglo se detecta esta división, según la cual el folklore afectaría a la cultura espiritual. del pueblo y la etnografía" (a veces, sencillamante artes popularesn) a la cultura material (artesanías, indumentaria, arquitectura, etc.). No es frecuente hoy encontrar en títulos bibliográficos, la denominación de folklore referida a la arquitectura, las técnicas o las artes plásticas llamadas populares. Sin embargo, aplicar aquí el término etnografía (o etnográfico) reduce, a su vez, el sentido y alcance de éste, ya que la etnografía es la descripción de todo el complejo cultural de un grupo, o de una parte de él que no tiene porqué identificarse con los aspectos tecnológicos y materiales.

Por otra parte, la reducción del estudio folklórico a la literatura y la música llamadas populares es, podría decirse, una desvirtuación también posterior del término, ya que, aunque pueda haber habido una tendencia a ocuparse preferentemente de estos aspectos del saber popular, en las definiciones antiguas de folklore (y también en las modernas) aparece un carácter mucho más general. Veámos la descripción de los contenidos del folklore propuesta por el introductor de estos estudios en España, Antonio 
Machado y Álvarez, en las Bases de cuya Sociedad, El Folk-Lore Español, aparecen marcados los objetivos:

Esta Sociedad tiene por objeto recoger, acopiar y publicar todos los conocimientos de nuestro pueblo en los diversos ramos de la ciencia (medicina, higiene, botánica, política, moral, agricultura, etc.); los proverbios, cantares, adivinanzas, cuentos, leyendas, fábulas, tradiciones, y demás formas poéticas y literarias; los usos, costumbres, ceremonias, espectáculos y fiestas familiares, locales y nacionales; los ritos, creencias, supersticiones, mitos y juegos infantiles en que se conservan más principalmente los vestigios de las civilizaciones pasadas; las locuciones, giros, traba-lenguas, frases hechas, motes y apodos, modismos, provincialismos y voces infantiles; los nombres de sitios, pueblos y lugares, de piedras, animales y plantas; y, en suma, todos los elementos constitutivos del genio, del saber y del idioma patrios, contenidos en la tradición oral y en los monumentos escritos, como materiales indispensables para el conocimiento y reconstrucción científica de la historia y de la cultura españolas (Machado, 1981: 501)

Aunque no existe gran acuerdo en la definición de folklore (Alcina, 1982; Leach y Fried, 1949), sí puede decirse que este aspecto totalizador y no reducido del objeto folklórico es contemplado por la mayoría. Así aparece en una de las propuestas más aceptadas (Bascom, 1974: 20):

Folklore significa sabiduría popular; abarca todos los conocimientos que se transmiten oralmente y todas las habilidades o técnicas que se aprenden por imitación o mediante el ejemplo, así como los productos resultantes. Los objetos fabricados en serie y los conocimientos adquiridos por medio de libros o de una educación formal son parte de la cultura, que comprende la totalidad del saber, pero no pertenecen al Folklore. En las sociedades no alfabetizadas, folklore se identifica con cultura, pero en las industrializadas, constituye solamente una parte de ella.

Otro problema permanente para la investigación folklórica ha sido el de la definición o concreción de un término para ella fundamental: "pueblo- (y popular). Aunque sin ser exactamente una referencia a clase social concreta, los folkloristas clásicos con "pueblo" aludían al vulgo; a las capas iletradas e incultas de la sociedad, a cuya burguesía ellos mismos pertenecian. Pero ni siquiera todas las clases subalternas se consideraban objeto folklórico, ya que los obreros industriales y las clases pobres urbanas en general no se pensaba que tuvieran un saber y sentir "tradicional. (por ancestral y antiguo), como era el caso de los campesinos, principales detentadores de esos rasgos folklóricos. Además, también entre los sectores modernos y urbanos existían hechos y formas de expresión folklóricas que habían permeado la cultura escrita y la ciencia.

Por otro lado, en el siglo pasado lo spopular, así considerado, es decir, como la cultura tradicional de las clases iletradas, preferentemente rurales, 
afectaba a amplios sectores sociales en todos los países europeos y, por tanto, el folklore podía ser también considerado como "cultura popular", en la acepción actual de cultura masiva; por el contrario, del folklore hoy no puede decirse que sea la cultura de masas que para muchos indicaría la palabra popular. De hecho, aunque es común la utilización del adjetivo "popular" para referirse a las obras del "pueblo" y, por tanto, a la creación folklórica, en un uso alternativo y/o equivalente a tradicional. (por ejemplo en cultura popular/cultura tradicional), no deja de haber folkloristas que establecen unas claras diferencias. Así, en palabras de Isabel Aretz (1972: 19):

Designamos con el nombre de popular a determinadas manifestaciones que surgen en las ciudades y circulan por todo el pueblo - sin hacer distinción de clases- y llegan hasta a convivir con lo folklórico, sin adquirir su carácter sino excepcionalmente y después de un largo proceso [...] lo folklórico, en cambio, es lo tradicional, lo que tiene larga trayectoria, lo que es propio del pueblo desde varias generaciones. Lo popular no necesita tener raiz nacional; lo folklórico si (las cursivas son de la autora).

Al hilo de esta última cita, y en relación con las anteriores, podría hablarse de una división en las definiciones de folklore entre aquellas que relacionan o enumeran los conocimientos que se considera incluidos en la llamada "sabiduría popular" y aquellas otras que insisten en la esencia o cualidad de dichos conocimientos (manifestaciones vernáculas, auténticas, antiguas, anónimas, espontáneas, etc. del pueblo) y que hacen hincapié en lo particular y propio frente a lo universal y estandarizado (Alcina, 1984: 46-47).

La dịcotomía culto-popular (acompañada muchas veces por la complementaria de ciudad-campo y, finalmente, élites-clases subalternas) ha sido uno de los motivos básicos de reflexión para el folklore, uno de los más fértiles y que han podido ser exportados a otras disciplinas como la historia, historia de la literatura o historia del arte.

Muy relacionada con esta idea del pueblo que, de forma esencialista, se define como un sujeto colectivo, detentador de las raíces, el fondo étnico, el carácter primigenio, la originalidad cultural, etc., de cada nación, sin concretar más, está otra cuestión también de difícil resolución. Se trata del problema de la diacronía del folklore. Porque, idealizado el pueblo como una especie de entidad orgánica, provista de sentimientos, conocimientos, intereses, etc., había que terminar de situarle en un tiempo igualmente ideal, originario y ancestral; el tiempo mítico de su gestación como tal pueblo- (Velasco, 1990: 132; Llopart, Prat y Prats, 1985: 9).

Por tanto, para los folkloristas del siglo xIX, una de las motivaciones 
más permanentes era la necesidad de rescatar para la historia nacional la sabiduría y las obras del pueblo que, pese a su importancia para el país ( $y$ en suma para conocer la evolución de la propia civilización occidental), no habían sido tenidas en cuenta por los historiadores. El aspecto reconstructivo, desde el presente hacia detrás, hasta llegar a los orígenes más remotos, era así un elemento consustancial a este folklore decimonónico, que había surgido al lado de la antropología y, como ésta, a partir de la teoría de la evolución. La recurrencia a cualidades como la tradición, la antigüedad, la herencia, lo originario, las transformaciones rápidas de la vida moderna, etc., indican que el folklore nacía como una disciplina de fuerte contenido historicista.

Sin embargo, la temporalidad histórica, los procesos de cambio, las innovaciones acumuladas, quedaron marginados por el dominio excluyente, y casi sagrado, de la tradición, que no supone término cronológico. Oralidad, anonimato y tradicionalidad eran los caracteres definitorios de la creación popular y ninguno de los tres parecía acomodarse bien a los preceptos metodológicos de la historia: documentación, autor, fecha. El folklore era inmutable, había permanecido extrañamente sin cambios durante siglos; era una especie de poso o sustrato geológico (Velasco, 1990: 129), el vestigio de una etapa de la evolución general de la humanidad (la barbarie) que todavía, sin embargo, podía llegar a contemplarse; era, así, algo muy distinto a la historia.

Por otra parte, la tradicionalidad, la oralidad y el anonimato convertían a los sujetos folklóricos (los individuos que mantenían ese "saber" del pueblo) en meros agentes de transmisión; no importaban sus circunstancias, su mundo real, sólo su "saber", en otras palabras: los textos. De esta manera, el objetivo fundamental del folklorista era el "rescate", la recopilación, la formación de archivos que contuvieran cuantas más muestras mejor de esa ancestral y anónima fuerza creativa popular. Este objetivo justificaba los métodos y la manera de presentar las investigaciones, y eximía a los folkloristas de acometer tareas de mayor alcance que las meramente recolectoras.

En el siglo XIX, este descriptivismo, el particularismo, la falta de una teoría científica que respaldara la investigación, se justificaba basándose en que el folklore era una ciencia joven, en que sus materiales eran hasta entonces desconocidos y en que, según los preceptos de la nueva ciencia positiva, la tarea básica para iniciar cualquier construcción válida, era obtener una base empírica de hechos de la cual extraer luego hipótesis y deducciones. Pero que no eran estas circunstancias iniciales las que impedían que el folklore se desarrollara como un conocimiento científico, lo demuestra el que, después de un siglo, se siga recurriendo a las mismas 
justificaciones basadas en la urgencia y la necesidad de salvar del olvido los últimos vestigios de la cultura tradicional (que, por cierto, a juzgar por su enorme capacidad de supervivencia no sólo no parece correr peligro de extinción, sino gozar de magnífica salud); así como que se mantenga que a esta labor de salvamento puede contribuir cualquiera que tenga interés, y se sigan empleando los mismos métodos de recolección descontextualizada de los datos. Así pues, los problemas metodológicos del folklore sólo pueden explicarse recurriendo a sus conceptos fundamentales, se originan precisamente en una teoría (Velasco, 1990: 134) y no se deben, como se ha señalado frecuentemente, a una ausencia de orientación teórica (Juliano, 1986: 14).

Volveremos luego sobre alguno de estos puntos, que han sido discutidos por folkloristas contemporáneos, cuando tratemos de las diferencias de la etnología con respecto al folklore. Pero, veámos ahora algo sobre el origen de la investigación folklórica en Europa, que resultará también esclarecedor.

\section{INICIOS DE LA INVESTIGACIÓN FOLKLÓRICA}

Evidentemente, mucho antes de que se acunara el término hubo quienes estudiaron los objetos folklóricos. En el Sur de Europa, los que pueden considerarse precursores tuvieron distintas motivaciones sucesivas para interesarse por la cultura popular. Resumiendo mucho, en primer lugar, hubo quien observó los usos y costumbres populares porque los consideró impregnados de cierto paganismo. En segundo lugar, los humanistas descubrieron también que había cierta continuidad entre los usos populares y los de los antiguos clásicos. En tercer lugar, los ilustrados se preocuparon de describir los errores supersticiosos que impedian el avance del "pueblo" hacia las luces, para combatirlos con la razón y la lógica modernas (Caro Baroja, 1985: 132-133).

Pero será después de la Revolución francesa cuando cundirá por toda Europa un verdadero entusiasmo por el pueblo. Este interés revestirá características diferentes en cada país o ambiente. Surgirá una corriente nacionalista, otra que será más bien racista (paneslavismo, pangermanismo, etc.), y otra que Caro llama epopulistan en esencia (Caro Baroja, 1985: 134-135). Aunque la aplicación a cada país es diferente, y depende mucho de la situación política y de la plasmación de los incipientes nacionalismos europeos, el concepto de pueblo cambia y pasa, de ser un acúmulo de errores y atrasos, a considerarse el depositario de una sabiduría preciosa, y no sólo eso; el poseedor de las esencias, del egenio", de la caracterización 
primigenia y diferente de cada nación, sea Alemania, Cataluña, Polonia... Hay, pues, que estudiarlo, como objeto preferente, en todas sus expresiones y manifestaciones, y esto se convierte en una obra "patriótica" en muchos países europeos.

Paralelamente a este proceso de reconocimiento nacional y rescate de las propias raíces culturales o étnicas, se produce en Europa, a mitad del siglo XIX, un proceso de expansión colonial e intelectual por todo el mundo, que llevaría, en última instancia, implícita la homogeneización, aunque fuera de forma superficial, de la diversidad cultural, según unos principios etnocéntricos. El contacto colonial determinó un desarrollo enorme de las incursiones etnográficas en culturas exóticas y, en consecuencia, de la etnología. Surge un primer paradigma que homogeneiza el disperso discurso antropológico, el evolucionismo cultural. Y éste es el que unifica, en principio, el inicio de las dos líneas de investigación: la dedicada al estudio de los pueblos primitivos, o diferentes a la civilización occidental, y la dedicada al estudio de la propia cultura o, más bien, como veremos, de una parte de ella.

Muy brevemente, diremos que el planteamiento teórico evolucionista consistía en pensar que era posible, en base al conocimiento de los representantes actuales (supervivientes), reconstruir toda la línea evolutiva (única) seguida por el hombre en lo social y en lo cultural, desde los orígenes, de enorme simplicidad, hasta la mayor complejidad posible, representada por la civilización occidental. En este esquema se incluían bien, tanto las investigaciones etnográficas sobre primitivos (que harían luz sobre el estadio de salvajismo humano), como las folklóricas, que veían incrustados en la propia cultura occidental, moderna, letrada y progresiva tecnológicamente, algunos atisbos de fases anteriores de evolución (la barbarie) por las que se habría ya pasado y de las que, no obstante, quedaban restos, atavismos, "supervivencias", en ciertos sectores. Estos sectores conservadores, atávicos, supervivientes, se configuran bajo la palabra "pueblo", refiriéndose con ella no a un criterio de clase social baja, sino - por influencia de la anterior idea romántica - al mundo rural, campesino, tradicional, que ya había sido idealizado como detentador de las raíces culturales ancestrales, e, incluso, del carácter colectivo (el "genio popular") de cada país.

En una definición de G. L. Gomme, secretario de la Folk-Lore Society of London, aparece este sentido estático y arqueológico que tuvo el folklore en sus orígenes ( $y$ del cual, hay que decirlo, todavía no se ha desprendido): :La ciencia folklórica radica en la tradición. No existe folklore moderno. El Folklore es una ciencia, la ciencia de las supervivencias" (Marcos Arévalo, 1987: 648). 
Así pues, para algunos historiadores actuales de la antropología, folklore y etnología son dos caras de un mismo tipo de principio general de conocimiento. Uno estudia lo diferente, lo exótico, de dentro de nosotros mismos: la diferencia interna. Otra se ocupa de lo exótico de fuera, de los otros: la diferencia externa. Muestra de que ambas líneas procedian de un mismo tipo de conocimiento -que hay que reconocer que luego dio lugar a dos diferentes disciplinas - es la obra de algunos autores que son incuestionablemente incluidos en la nómina de los antropólogos. Entre ellos, el más conocido para nosotros es, sin duda, J. Frazer y su obra monumental La Rama Dorada, en la que se ve un acopio de datos de origen muy diverso y adquiridos por método etnográfico, arqueológico, lingüístico, literario, etc., incluyendo, por supuesto, una enorme cantidad de elementos folklóricos, al servicio de una teoría antropológica.

De todas formas, esta visión no es compartida por algunos autores, que ven la actual separación del folklore y la antropología sociocultural con profundidad histórica. Ambas disciplinas se originarían en tradiciones teóricas distintas. El evolucionismo sería la base de partida de la antropología, y el romanticismo sería el movimiento del que surgió el folklore, respondiendo a "distintas concepciones del mundo" (Juliano, 1986: 4). Esta interpretación histórica puede estar determinada por la visión actual de las dos disciplinas y, concretamente, por el acercamiento de los antropólogos sociales a la cultura popular como objeto de estudio, antes considerada sólo terreno de los folkloristas. Tal acercamiento se produce desde posiciones teóricas y con metodologías que se reclaman antropológicas y, por tanto muy diferentes y alejadas de la investigación llevada a cabo clásicamente por el folklore. Así, es útil resaltar la diferencia de origen de antropología y folklore y afirmar que su "encuentro actual es el resultado de un proceso de confluencian (Juliano, 1986: 11), por más que en esta argumentación no puedan dejar de observarse ciertas contradicciones, y no sólo historiográficas.

\section{DIFERENCIAS ENTRE ETNOLOGÍA Y FOLKLORE}

El mostrar estos orígenes comunes no quiere decir que haya indeterminación entre las dos disciplinas; más bien al contrario. Al menos desde la perspectiva actual, no habría muchas cosas que resultaran más molestas para un "antropólogo" académico que el confundirle con un folklorista clásico. En este sentido, algunos etnólogos, como Claudio Esteva (1980), se han interesado por mostrar las diferencias entre ambos trabajos, desde el punto de vista más riguroso -el teórico y metodológico-, sin caer en 
ningún tipo de menosprecio ni basarse en consideraciones de sociología de la ciencia. La primera diferencia claramente apreciable ya ha sido expuesta. Mientras que el objeto clásico de la etnología era el estudio de los grupos de cultura llamada "primitiva", el folklore se constituía, paralelamente, en una especie de etnología de nosotros, que estudiaba las tradiciones culturales propias de los pueblos europeos, en particular aquellas que empezaban a ser sustituidas por el desarrollo de las nuevas formas de vida y conocimiento, y las instituciones que las acompañaban (sociales, económicas, religiosas, educativas, etc.). En este sentido, el folklore fue considerado como una especie de etnología de urgencia, aplicada al rescate del conocimiento de una cultura que antes no se había valorado y que desaparecía rápidamente (Esteva, 1980: 131-132; 1989: 15-16).

Un aspecto esclarecedor de que esta división, nuestra cultura-las otras, funciona en la división etnología-folklore, lo tenemos en la investigación de América Latina. Allí, la riqueza de la variedad cultural ha contemplado, hasta hace muy poco, e incluso en la actualidad, la convivencia (o malvivencia) de sociedades sencillas y étnicamente indígenas y otras mestizas en muy diferentes grados y situaciones, y más complejas en sus estructuras. En estos países se produciría, por tanto, la mejor situación para que el folklore se hubiera extendido como estudio antropológico dominante. Si recordamos la definición dada por Bascom (citada más arriba), que dice que en las sociedades no alfabetizadas, folklore se identifica con culturan, es evidente que los folkloristas deberían haber estudiado esos grupos indígenas, con una cultura toda ella basada en la transmisión oral de los conocimientos y pautas tradicionales. Esto no es, ciertamente, lo que ha ocurrido. Aunque en los países de Centro y Sur América, como ha pasado también en EEUU, el folklore ha tenido una introducción académica notable y no sufre el, diríamos, desprestigio que, como tal disciplina, ha tenido en el mundo europeo, los profesionales "encargados" de estudiar las culturas indígenas, y en gran parte también las mestizadas con mayor peso aborigen, han sido los etnólogos. Los folkloristas se han centrado, al menos hasta hace relativamente poco, en el campo de la literatura, usos y costumbres tradicionales, de ámbito campesino, que pueden ser aducidas como señas de identidad de los diferentes países o comunidades complejas. Es decir, en su campo clásico (Arezt, 1972: 42; Alcina, 1982).

Pero se han establecido otros puntos de diversidad, quizá más profundos, aunque también determinados por la anterior diferencia. Al abordar el estudio de las sociedades tribales, los etnólogos las contemplaban como una totalidad. El modelo etnográfico tendía hacia una descripción completa en la que debían tener cabida las distintas categorías del comportamiento cultural: materiales, sociales e ideológicas, cognitivas o espirituales. En 
consecuencia los grupos aparecían con existencia real (o al menos eso se pretendía). Incluso, este mismo criterio globalizador aparecía aplicado a Europa, y el folklorista y el etnólogo se diferenciaban por el enfoque particular del primero y holístico del segundo; de forma que los etnólogos tendían a escribir monografías globales sobre, por ejemplo, los vascos, los escoceses, etc. (Esteva, 1989: 17).

Por su propia definición, el folklore tenía que diferir de los objetivos generalizadores de la etnología. No trataba con culturas completas, sino con etapas o niveles de cultura dentro de la "civilización", y en vez de describir grupos concretos, se enfrentaba con "pueblos", cuyo rasgo distintivo fundamental consistía precisamente en ser los generadores de conocimientos y hechos folklóricos. Así, el folklore actuaba sobre particularidades segmentadas, la misma cultura popular, y dentro de ella, su labor consistía en documentar y rescatar costumbres, pero no todas, sólo aquellas que podían ser consideradas arcaicas y demostraban ser únicas o peculiares (Esteva, 1989: 18). Además, el esencialismo característico de la definición de "pueblo" o "tradición", obligaba a los folkloristas a incidir, en sus recopilaciones, en aquellos datos o expresiones que contribuian a la demostración de la existencia de un alma o espíritu creativo particular, y a dirigir las investigaciones hacia aquellos rasgos culturales que tienen que ver con la ética $y$, sobre todo, con la estética. Si al antropólogo le ha guiado una intención de reconstrucción del "contexto" en el que los individuos desenvuelven su vida $-\mathrm{y}$ por eso la etnografía intenta ofrecer descripciones integradas de todos los aspectos del comportamiento social, desde los materiales a los de carácter simbólico o religioso- al folklorista, en cambio, le ha interesado el texto, no tanto el contexto; el hecho particular, su forma, no sus problemas de dinámica y función (Díaz Viana, 1984: 153-54; Velasco, 1990: 133). Lo que se considera objeto es la fiesta, por ejemplo, aunque sea desgajándola del tejido social donde se produce, o el romance, con independencia de todo el discurso cognitivo que rodea la transmisión de la literatura oral.

Dos aspectos fundamentales, el particularismo (y la descontextualización) y el excesivo recurso al descriptivismo (la recolección de documentos únicos), han sido los que se han esgrimido para tachar al folklore de conocimiento no científico y de pobreza teórica. El objetivo fundamental de colectar y la atención al texto aislado son, a la vez, las bases que sustentan lo que podría llamarse el adiscurso folklóricon, es decir, la manera clásica en que los especialistas presentan los resultados de la investigación. H. Velasco (1990: 134-139; 1994) ha analizado la lógica de este discurso, sobre la base de que los trabajos folklóricos son fundamentalmente colecciones de textos, atribuidos a un sujeto colectivo, caracterizado 
como pueblo, y circunscrito a un ámbito que puede ir desde la localidad, a la comarca, provincia, región, Estado o nación sin Estado (Velasco, 1990: 134).

Los objetivos y presupuestos generalizadores estaban, por el contrario, en el mismo origen de la antropología cultural que pretendía la creación de modelos generales, capaces de extenderse a toda la humanidad, a partir del estudio de la variada tipología de situaciones culturales distintas observables. Frente a esto, la utilidad teórica del particularismo folklorista era más difícil de apreciar; parecía consistir en un interminable proceso acumulativo, desprovisto de crítica y sin una funcionalidad muy precisa (aunque incluso pudiera ser muy válido para otras materias, como la literatura y la misma etnología). Pero lo que no es cierto es que el folklore estuviera desprovisto de principios teóricos (cf. Juliano, 1986: 13-14).

En primer lugar, conviene recordar la existencia en el momento del surgimiento de la disciplina de un sistema teórico al que el folklore se asimila, el evolucionista. Posteriormente, otros complejos teóricos, difusionismo, funcionalismo, estructuralismo, han tenido improntas muy fuertes en la labor investigadora de los folkloristas (recordemos, por ejemplo, los esquemas de V. Propp). Pero el problema parece no ser éste; parece que el particularismo del folklore está apoyado, más que en otros, en elementos ideológicos (Prat, 1985). El concepto de "pueblo" que planteaba obedecía a la búsqueda de un sujeto en que encarnar un concepto de nación. Aparte de que el folklorista intente racionalizar y explicar las costumbres, atribuyéndoles un sentido arcaico o de otro modo, la motivación más profunda de su labor es descubrir lo propiamente eétnico", la personalidad tradicional. La parodoja de esta búsqueda ha sido puesta de manifiesto por autores como H. Velasco $(1988 ; 1990)$. Tampoco conviene olvidar la enorme vigencia de este pensamiento en la actualidad entre nosotros, en función de la cual pueden entenderse los grandes apoyos institucionales que recibe la investigación y el espectáculo folklórico (Martí, 1990). A medida que el concepto "pueblo" se iba convirtiendo sobre todo en un símbolo pleno de muy diversos significados, para la sociedad moderna, la recuperación de sus saberes y formas expresivas superaba el ámbito de la mera investigación particular para pasar a ser una labor social y política, apoyada en las extensiones adquiridas por el pueblo como nación o clase social (Velasco, 1988: 27). Este camino, en realidad, estaba ya planteado en los mismos orígenes del folklore. El Romanticismo buscaba en la cultura tradicional la posibilidad de encontrar las raíces más profundas de lo propio y, en torno a éstas, reforzar la identidad. La idealización de este sustrato de originalidad y diferencia étnica era, en realidad, un instrumento para crear o desarrollar una conciencia nacional 
que incluso podía estar totalmente perdida (Esteva, 1989: 18). Esta idea produjo el desarrollo del trabajo folklórico en muchos países y no es ajena a nuestra realidad actual, lo que lleva a pensar que existe una relación consustancial entre folklore y nacionalismo, quizá del mismo estilo de la que algunos autores plantean entre colonialismo y etnología.

\section{CONFLUENCIAS ENTRE FOLKLORE Y ETNOLOGÍA}

Sin pretender entrar en una discusión acerca de la relación que, como tales disciplinas, han mantenido etnología y folklore - y que yo, personalmente y refiriéndome al caso español, reduciría a menosprecio evidente de los practicantes de la primera hacia los de la segunda-, lo que parece evidente en la actualidad es que existe una mayor disposición a la colaboración y a la aceptación mutua, que puede estar producida por las crisis habidas en las dos materias en los últimos tiempos.

Es claro que en el campo del folklore se manifiesta, a partir de los años setenta, una renovación liderada por algunas escuelas, como la norteamericana que se ha planteado con toda seriedad los problemas básicos de su disciplina: Alan Dundes (1975; 1980; 1989), Richard M. Dorson (1972; 1978) o Stanley L. Robe (1967) son figuras importantes en esta revisión; sin olvidar que también en Europa tuvo lugar, incluso con cierta antelación, un movimiento renovador representado por autores como Hermann Bausinger (1961, 1993). Pero hay que reconocer, a la vez, que la superación de los reductores postulados funcionalistas que imperaron en la antropología y la apertura de ésta hacia otros posibles objetos de estudio (no primitivos) y enfoques muy abiertos teóricamente (acercamiento a la semiología, la literatura, el mismo campo de la cognición) han propiciado el acercamiento sin prejuicios al terreno de investigación del folklore (Luque Baena, 1989: 51). Esta confluencia parte de un punto de encuentro básico y fundamental, que es que el folklore debe ser considerado como una disciplina antropológica; si debe mantenerse diferenciada o debe ser asimilada por la etnología es asunto más discutible y no entraremos en ello.

Entre los aspectos de renovación de la investigación folklórica, algunos autores (Esteva, 1980: 153-162; Díaz Viana, 1984) han señalado aquéllos fundamentales. Siendo lo más importante el cambio producido en qué es lo que estudia el folklorista. En primer lugar, los autores norteamericanos han puesto en duda la práctica de la mayor parte de sus colegas europeos de seguir relacionando la idea de folklore con las capas iletradas de la sociedad, contraponiendo siempre lo culto y lo popular. El *moderno 
concepto de folklore (Díaz Viana, 1984: 148) amplía considerablemente el campo, haciendo posible que se hable de un folklore urbano, y de un folklore que se crea ahora mismo entre determinados grupos de edad, en círculos de profesionales, clases altas, etc., en relación con la industrialización y la tecnología (Dorson, 1978: 25-36), o con la cultura de masas (Schenda, 1994).

En segundo lugar, y según esto, se rompe el esquema clásico del estatismo de la tradición y se hace hincapié en la dinámica y creación constantes inherentes al folklore. Este punto pone en duda la imperiosa necesidad de rescate de antiquísimos tesoros perviviendo mágicamente, en que se han justificado la mayor parte de nuestros folkloristas: interesa más el fenómeno de creación y transmisión, que la simple recopilación de textos o hechos aislados. Se busca una verdadera metodología que sirva en la apreciación de qué es realmente el folklore y que, a la vez, pueda liberar a la disciplina de la categoría de materia auxiliar de la historia, la literatura o la lingüística, que han instrumentalizado tradicionalmente la investigación folklórica como fuente no problemática de útiles datos sobre ciertos hechos o sectores, habitualmente no bien atendidos o conocidos por ellas.

Por otra parte, y de forma frontal, se ponen en duda algunos de los criterios básicos empleados por los investigadores anteriores para identificar los materiales folklóricos. Por ejemplo, la antigüedad y la oralidad. La puesta en evidencia de que materiales escritos e impresos de muy diversa índole y otras formas de transmisión han convivido con la sagrada "tradición oral" y contribuido considerablemente en la formación de numerosas manifestaciones folklóricas, que además no se remontan en el tiempo más que a una época cercana y contemporánea, coloca a los folkloristas en un dilema muy gráficamente expresado por A. Dundes, en 1978, en una frase que reproduce L. Díaz (1984: 149):

\footnotetext{
Excepto por el criterio de oralidad, este material sería aceptado como Folklore por la mayor parte de los folkloristas norteamericanos. Ya que estos materiales no pertenecen en absoluto a la tradición oral, sólo nos quedan dos caminos: o tiramos a la papelera los datos recopilados o tiramos abajo la teoría.
}

Otro aspecto que ha sido superado por los folkloristas más vanguardistas es la definición de popular como parte de un binomio enfrentado por un lado a lo culto y por otro a lo urbano. La discusión sobre la *cultura popular. estaría centrada, por parte de los historiadores socio-culturales, en la caracterización del sistema amplio dentro del cual pudiera hablarse de cultura de élite frente a la cultura iletrada, y las interacciones y campos 
de actuación que puedan definirse en este aspecto, incluyendo la crítica de la bipolarización que el modelo culto/popular conlleva en la visión de la historia cultural occidental y las sucesivas matizaciones y reservas al empleo de la forma "cultura popular" (un buen ejemplo de esta línea de investigación en Burke, 1991).

Los folkloristas más ligados a la tradición filológica y más alejados de la antropología cultural, siguen manteniéndose apegados a la división clásica popular/élite y trabajando más que nada en relación con los textos, en los que se buscan precisamente las interacciones entre literatura culta y literatura popular. De acuerdo con la disciplina de la que proceden - la historia de la literatura- sus investigaciones parten de modelos historicistas y de crítica textual, que aplican a la literatura popular, de la misma forma en que sus colegas proceden con la literatura a secas. Metodológicamente, se centran en géneros (lírica, cuentística, etc.) que abordan en un sentido intercultural (Esteva, 1980: 159). Es decir, se intenta descubrir el origen, a través de la aparición más antigua en una fuente escrita (si la hay), de determinada variante de romance o tipo de motivo de cuento - por ejemplo- para, luego, clasificar y hacer tipologías; someterla a un exhaustivo análisis formal, y ver su extensión en una dimensión que puede ser universal; lo que constituiría su thistoria. y su "geografía. La prestigiosa escuela finesa sería el prototipo de este tipo de investigación folklórica.

No obstante, dentro de esta línea de tradición filológica y literaria se dio un movimiento de renovación, propiciado por los trabajos de Roman Jakobson sobre el lenguaje y su aplicación al campo del folklore. Muy tempranamente, en 1929, Jakobson y el folklorista ruso Petr Bogatyrev, en un artículo titulado "El folklore como forma específica de creación", ya planteaban cómo las manifestaciones folklóricas individuales eran asumidas por una determinada comunidad e integradas en su código expresivo de una manera parecida a lo que la lingüística estructural exponía con respecto al habla y la lengua (Schenda, 1994: 25). A partir de Bogatyrev fueron muchos los folkloristas que enfocaron su estudio con una perspectiva eminentemente funcional, que hizo cambiar el peso específico desde los textos a los contextos, de las piezas literarias a las gentes y las situaciones en que se necesitan o se utilizan. Como se ha señalado, esta evolución teórica ha sido el punto de partida para que se produjera un verdadero acercamiento de intereses entre folkloristas y antropólogos (Esteva, 1980: 159).

Asimismo, la introducción de un enfoque funcional en la conceptualización del folklore ha producido la posibilidad de afrontar el problema de la definición de lo folklórico saliéndose de la oposición habitual po- 
pular/culto. Se trataría de identificar una serie de códigos expresivos que implican la existencia de patrones de comportamiento determinados en distintos grupos que comparten algún rasgo común. Este rasgo no tiene porqué verse relacionado sólo con la rusticidad (campesinos iletrados), sino que puede ser de carácter étnico, derivado del desempeño de cierta actividad profesional, o de otros variados tipos; es el que produce una cierta identidad frente a otros grupos y el que posibilita la creación de un determinado y propio folklore (Díaz Viana, 1984: 152).

En último término, el folklore pasa a ser definido como una estética colectiva y no tanto como forma cultural de un supuesto grupo social, el popular, que ha resultado ser poco aprehensible. Analizar y reconstruir las normas que rigen esta estética colectiva será, pues, el objeto del folklorista. Este ámbito puede ser también de interés para el etnólogo, pero es posible diferenciar el enfoque. El folklorista, en general, tenderá a emprender su estudio desde el mismo hecho (performance, representación) folklórico; mientras que para el antropólogo esa representación será un elemento más en el análisis general de la comunidad o grupo de que se trate. En palabras de Díaz Viana (1984: 153), "El folklorista estaría, así, especializado en el estudio de los mecanismos creativos de la gramática estética de una colectividad.

Según esta nueva visión el folklore se caracteriza como “... tradición cultural que, dentro o fuera de nuestro ámbito, posee unas peculiares formas de creación, codificación y transmisión: el anonimato, la estructura abierta, la participación colectiva, y -sobre todo- la múltiple vida en el espacio y en el tiempo de sus creaciones" (Díaz Viana, 1994: 186). Y, evidentemente, esto es algo que está dentro de la antropología. Así enfocado, el folklore no tiene nada que ver con su imagen de etnología atrasada y pseudocientífica, incluso precursora de la moderna. Aunque, en gran medida, esta imagen siga permaneciendo entre los antropólogos -influyendo en ello que pueda haber más folklorismo que buena investigación folklórica; como también, en palabras de Luque Baena (1989: 5152), más antropologismo que antropología -, lo cierto es que el folklorista más que el erudito de costumbres y antiguallas de su pueblo (o mejor Comunidad Autónoma), debe ser, y ser visto como, un científico social que observa e interpreta una realidad concreta y especial, dinámica y múltiple en sus desarrollos y cambios.

A pesar de todo, en nuestro país, entre los antropólogos sociales, ha habido una cierta preferencia por seguir manteniendo la existencia - y reclamar el estudio- de una "cultura popular" que prefiere identificarse como una cultura de clase; concretamente, la producida por las clases subalternas o dominadas (Frigolé, 1985). Lo que supone retomar, en buena 
medida, el sentido que tuvo el folklore a partir de fines del siglo XIX (con sus constantes referencias al vulgo), pero sin asumir el nombre -folklore- ni los aspectos de particularismo, arcaismo y supervivencia que también incluía, y que para estos modernos defensores de la existencia de la cultura popular eran resultado de un conocimiento conservador y falto de teoría, preocupado por el mantenimiento acrítico del pasado. Su interés por la cultura popular reivindica, por el contrario, una filiación muy diferente - los planteamientos marxistas desarrollados por A. Gramsci- y un compromiso con el cambio social (Juliano, 1986: 12-14).

Sin embargo, la identificación de "cultura popular" con cultura dominada, subalterna o de las clases subalternas, opuesta a la cultura dominante, hegemónica o burguesa, presenta ya de por sí abundantes problemas teóricos que han sido señalados por algunos críticos de esta corriente (Esteva, 1989: 20-23). Pero, sobre todo, la cuestión parece provenir de una contradicción difícilmente soslayable; y es que, a pesar del interés puesto por los antropólogos sociales que trabajan en este campo por separarse de lo que hacen los folkloristas, en la práctica, los resultados, los esquemas empleados y las temáticas tratadas no resultan tan diferentes en esta llamada "cultura popular", de lo que aparece en la que los otros califican como "cultura tradicional" (Esteva, 1989: 20; Mira, 1985: 24). Es decir, que el análisis de la cultura, o culturas, de la clase o clases subalternas supone inevitablemente una vuelta (por muy actualizada que sea) a la bipolarización social reflejada en la interpretación básica de la cultura hecha por el folklore clásico, dado que no es posible caracterizarla sino en un sistema más amplio, dentro del cual se define por su oposición y resistencia a la producida por las clases dominantes. Así, por mucho que se pretenda la superación de la dualidad habitual rural/urbano, tradicional/ moderno, iletrado/élite, se está insistiendo, contradictoriamente, en parecidos tópicos teóricos y sociales a los que se critican (Llopart, Prat y Prats, 1985: 11).

Parece evidente que otros aspectos, además de la clase social, contribuyen en nuestra sociedad a la creación y el mantenimiento del folklore, sean éstos étnicos (Esteva, 1989: 23-27), políticos, contraculturales, de mercado de masas, etc., $y$, tal vez - como se ha expuesto en la introducción de un libro bastante difundido sobre este tema-, haya un elemento básico de resistencia que los una:

la cultura popular o, més ben dit, els diferents discursos sobre la cultura popular apareixen sempre com a raonaments alternatius a la prepotència del model de societat capitalista, d'Estat i de classe. En tots els casos s'emfasitzen aquells aspectes -les formes de vida i els valors pre-industrials, les formacions nacionales sense Estat $i$ les classes subalternes respectivament- que ocupen espais marginals i de 
subordinació respecte a les estructures dominants esmentades (Llopart, Prat y Prats, 1985: 11).

Quizá, añadiría yo, la posición no igualitaria de "lo popular", en los términos en que aparece descrita arriba, podría haber llegado a reflejarse también en la diferente consideración obtenida por el folklore y la antropología social como disciplinas científicas.

\author{
CARMEN ORTIZ GARCIA \\ Instituto de Filología, \\ CSIC, Madrid
}

\title{
BIBLIOGRAFÍA
}

Alcina Franch, José, 1982: "El folklore de España e Iberoamérica", Resumen del Primer Congreso Iberoamericano de Estudiosos del Folklore, Las Palmas: Mancomunidad de Cabildos de las Palmas/Ministerio de Cultura, sin paginar.

- 1984: -El folklore como antropología, en S. RODRígUEz BECERRA (ed.), Antropología cultural de Andalucia, Sevilla: Junta de Andalucía, 45-60.

ARETZ, ISABEL, 1972: Manual de folklore, Caracas: Monte Ávila Editores [1. ${ }^{a}$ ed. 1955].

BASCOM, WILLIAM, 1974: ‘Folklore", en D. L. SILls (ed.), Enciclopedia Internacional de las Ciencias Sociales, Madrid: Aguilar, V, 20-23.

BAUSINGER, HeRmanN, 1961: Volkskultur in der Technischen Welt, Stuttgart: W. Kohlhammer.

- 1993: Volkskunde ou l'ethnologie allemande, Paris: Éditions de la Maison des Sciences de l'Homme [ed. original 1971].

Bogatyrev, PETR y JaKobson, Roman, 1929: .Die Folklore als eine besondere Form des Schaffens, en Donum natalicium Schrijnen. Verzameling van opstellen door ondleerlingen en breviende vakgenooten..., Nijmegen/Uthrecht: Dekker \& Van de Vegt, 900-913 [versión española en R. JAKOBSON, Ensayos de poética, México: FCE, 1977, 7-22].

Boggs, RalPh SteEle, 1945: -Reprint of the letter by W. J. Thoms in The Athenaeum of August 22, 1846, first proposing the word 'Folk-Lore', with spanish translation, Folklore Américas, $\mathrm{V}, 2$.

BURKE, PETER, 1991: La cultura popular en la Europa moderna, Madrid: Alianza led. original 1978].

Caro Baroja, Julio, 1985: "El movimiento folklórico europeo y sus dimensiones", en Los fundamentos del pensamiento antropológico modemo, Madrid: CSIC, 131-143.

DfAZ VIANA, LUIS, 1984: -El folklore dentro de las disciplinas antropológicas: Tradición y nuevos enfoques, Ethnica, 20, 145-155.

- 1994: -Sobre las definiciones de folklore: viejos condicionamientos y nuevos enfoques, en Actas do Simposio Internacional de Antropoloxia. In memoriam Fermín Bouza-Bney, Vigo: Consello da Cultura Galega, 179-188. 
DORSON, RICHARD M. (ed.), 1972: Folklore and Folklife. An Introduction, Chicago/ London: The University of Chicago Press.

- 1978: "Folklore in the Modern World", en R. M. Dorson (ed.), Folklore in the Modern World, The Hague/Paris: Mouton, 12-51.

Dundes, AlAn (ed.), 1965: The Study of Folklore, Englewood Cliffs: Prentice-Hall Inc.

- 1975: Analytic essays in Folklore, The Hague/Paris: Mouton.

- 1980: Interpreting Folklore, Bloomington: Indiana University Press.

- 1989: Folklore Matters, Knoxville: The University of Tennesse Press.

- y PATger, CARL R., 1978: Work Hard and You Shall Be Rewarded: Urban Folklore from the Paperwork Empire, Bloomington: Indiana University Press.

ESTEVA FABREGAT, ClAUdio, 1980: "El folklore en el contexto de la antropología cultural", en La Antropología Americanista en la Actualidad, México: Editores Mexicanos Reunidos, II, 131-164.

- 1989: "Antropología, folklore e identidad cultural, en J. MARCos y S. Rodríguez (eds.), Antropologia Cultural de Extremadura, Mérida: Asamblea de Extremadura/ Editora Regional de Extremadura, 15-33.

Frigolé, JOAN, 1985: “Cultura popular i sistema de classes: una breu notan, en D. Llopart, J. Prat i ll. Prats (eds.), La cultura popular a debat, Barcelona: Fundació Serveis de Cultura Popular/Alta Fulla, 87-89.

Juliano, DOlores, 1986: Cultura popular, Barcelona: Anthropos (Cuadernos de Antropología, núm. 6).

LeACH, MARIA y FRIED, JEROME, 1949: Funk and Wagnalls Standart Dictionary of Folklore, Mithology and Legend, New York.

LUQue BAENA, ENRIQUe, 1989: -Antropólogos y folkloristas: Desencuentros y confluencias", El Folklore Andaluz, 4, 49-58.

LLOPART, DOlORS; PRAT, JOAN y PRATS, LloRENÇ, 1985: „Presentació,, en la cultura popular a debat, Barcelona: Fundació Serveis de Cultura Popular/Alta Fulla, 5-12.

MACHAdo Y Álvarez, ANTONIO, 1981: .El Folk-Lore Español. Sociedad para la recopilación y estudio del saber y de las tradiciones populares. Bases", en El Folk-Lore Andaluz, Sevilla: Tres-Catorce-Diecisiete, 501-503 [ed. original 1882].

- 1987: :Sobre el Folk-Lore•, El Folklore Andaluz (segunda época), 1, 15-22 led. original 1882].

MARCos ARÉvalo, JAVIER, 1987: .El folklore desde la antropología cultural., Revista de Estudios Extremeños, XIIII, 645-660.

- 1988: :Folklore", en A. AGUIRRE (ed.), Diccionario temático de antropología, Barcelona: PPU, 376-387.

MARTf I PÉREZ, JOSEP, 1990: •El folklorisme. Anàlisi d'una tradició 'prêt à porter'•, Anuario Musical, 45.

Mira, Joan F., 1985: "De cultivats, rurals i rústics", en D. Llopart, J. Prat I Ll. Prats (eds.), La cultura popular a debat, Barcelona: Fundació Serveis de Cultura Popular/ Alta Fulla, 24-27.

Prat I CARÓS, JOAN, 1985: -El folklore catalán: ¿ideología o ciencia?,, en Actas del II Congreso de Antropología, Madrid: Ministerio de Cultura, 110-120.

ROBE, STANLEY L., 1967: -Contemporary trends in Folklore Research., Latin American Research Review, II, 2, 26-54.

SCHENDA, RUDOLF, 1994: -Folklore y cultura de masas-, RDTP, XLIX, 2, 25-38.

Velasco Mafllo, Honorio M., 1988: -El evolucionismo y la evolución del Folklore, $E l$ Folklore Andaluz, 2, 13-32. 
- 1990: •El folklore y sus paradojas", Revista Española de Investigaciones Sociológicas, 49, 123-144.

- 1994: "La tradición oral. Un ensayo sobre la confusión entre textos y procesos", en Actas do Simposio Internacional de Antropoloxía. In memoriam Fermín Bouza-Brey, Vigo: Consello Da Cultura Galega, 179-188.

Se intenta una aproximación general a los puntos de confluencia y diferencia que, tanto históricamente como en la actualidad, han caracterizado la relación entre folklore y etnología. En primer lugar se examinan algunas cuestiones conceptuales sobre la definición, contenidos y orígenes de la investigación folklórica. A continuación, se exponen los factores teóricos y metodológicos que han contribuido de forma clara a diferenciar el trabajo folklórico y etnológico, para terminar analizando las líneas abiertas, tanto por los folkloristas como por los antropólogos, que suponen un acercamiento de las dos disciplinas dentro del marco amplio de las ciencias antropológicas, con especial referencia al caso de España.

A general approach is attempted about the similarities and differences that have characterized, historically and in the present day, the relationship between folklore and ethnological studies. Firstly a conceptual outline is made of the meaning, origins and scope of the folklore research. Next the apparent theoretical and methodological differences between the two research domains are analyzed, and finally an account is given of the open research lines, both by folklorists and ethnologists, that today contribute to unify the two fields of study in the broad context of the anthropological sciences, with special reference to the Spanish research. 